\title{
Analisis kualitas sambungan Alumunium 2024 menggunakan metode Friction Stir Welding (FSW) dengan variasi Kekerasan Material Pin
}

\author{
Istyawan Priyahapsara*, Sri Mulyani \\ Departemen Teknik Dirgantara, Sekolah Tinggi Teknologi Adisutjipto, Yogyakarta \\ Email Korespondensi : istyawanpriyahapsara@gmail.com
}

\begin{abstract}
Abstrak. Friction Stir Welding (FSW) sudah menjadi salah satu pilihan mutakhir dalam penyambungan struktur pesawat terbang berbahan paduan alumunium 2024 T3. Salah satu parameter penting dalam kualitas pengelasan FSW adalah material pin dengan kekerasan berbedabeda. Tujuan penelitian ini adalah untuk mengetahui pengaruh kekerasan material pin terhadap kualitas sambungan secara visual dan kekuatan mekanis sambungan FSW. Tiga jenis material logam digunakan dalam penelitian ini baja ST60, baja ST60 yang dikeraskan, dan baja stainless steel (SS). Material yang disambung alumunium paduan 2024 yang merupakan material untuk struktur skin pesawat terbang. Penyambungan menggunakan mesin mill dengan putaran spindle $1800 \mathrm{rpm}$, dengan sudut kemiringan pin $3^{\circ}$. Pengujian kekerasan pin, pencatatan temperatur pengelasan, pengamatan visual hasil pengelasan, pengujian tarik dilakukan secara berurutan. Pengujian tarik dilakukan dengan standar ASTM E8, dengan menggunakan mesin Go Tech berkapasitas $30 \mathrm{~T}$. Secara visual, ketiganya memperlihatkan topografi pengelasan yang cukup baik dengan rigi-rigi yang rapat. Hasil pengujian kekerasan didapatkan logam SS menghasilkan kekerasan tertinggi dengan nilai $1519.67 \mathrm{HV}$, diikuti ST60 hardened sebesar $1055.73 \mathrm{HV}$, dan paling kecil adalah ST60 sebesar $820.81 \mathrm{HV}$. Kekuatan tarik terbesar diperoleh pada sambungan menggunakan material ST60 hardened dengan nilai $294 \mathrm{MPa}$, diikuti SS sebesar $259 \mathrm{MPa}$ dan paling kecil adalah ST60 dengan nilai $232 \mathrm{MPa}$.
\end{abstract}

Keywords: $f s w$, join, tool, tensile strength

\section{Pendahuluan}

Friction Stir Welding (FSW) merupakan jenis pengelasan kondisi padat (solid state) yang mampu menghasilkan kualitas tinggi meskipun untuk logam yang sulit dilas seperti alumunium. Kemampuan ini menyebabkan metode ini menjadi pilihan mutakhir dalam penyambungan strukur pesawat terbang yang kebanyakan bermaterial alumunium [1]. Proses penyambungan rivet tetap menjadi pilihan utama dalam penyambungan struktur pesawat terbang karena alasan portable. Meskipun demikian dalam beberapa tahun mendatang FSW akan siap menggantikan rivet. Beberapa kelebihan FSW adalah ramah lingkungan, kekuatan sambungan lebih baik, hemat material [2]. Penyambungan FSW dimulai dengan gesekan (friction) akibat kontak antara pin yang berputar dengan logam yang disambung, gesekan ini menghasilkan panas (di bawah temperatur cair logam) sehingga logam melunak. Selanjutnya akibat putaran pin, logam lunak teraduk (stir) dan menyatukan logam yang sebelumnya terpisah. Kedua logam yang sudah teraduk pada akhirnya akan memadat bersama dan terjadilah proses pengelasan (welding) [3]. Dalam FSW, ada beberapa parameter yang bisa dikendalikan faktornya, spindle speed, feed rate, geometri 
tool [4]. Material juga mempengaruhi pembangkitan panas saat terjadi gesekan [5]. Penelitian mengenai efek sudut kemiringan (tilt) pin telah diteliti oleh Dialami [6], pada penelitian tersebut dilakukan pemodelan FSW dengan sudut $0^{\circ}$ dan $2.5^{\circ}$. Di simpulkan bahwa karena tingginya temperatur, semakin lunak material dan semakin besar gaya gesek pada sisi tool, aliran material pada sisi belakang tool FSW menjadi lebih baik, karena membatu pencegahan terjadinya cacat las. Riyadi [7], meneliti pengaruh variasi RPM dan diameter pin FSW pada alumunium 5083 terhadap kekuatan tarik, impak, dan mikrografi. Hasil penelitian didapatkan diameter tool pin $10 \mathrm{~mm}$ menghasilkan rerata kekuatan tarik sebesar 145.11 MPa. Modulus elastisitas terbesar didapat pin tool diameter $8 \mathrm{~mm}$ sebesar $10.18 \mathrm{MPa}$ dan kekuatan impak sebesar $0.085 \mathrm{~J} / \mathrm{mm}^{2}$. Nik [8], 2017, meneliti variasi bentuk pin FSW untuk penyambungan polypropylene, hasilnya adalah bentuk pin silindris menghasilkan tegangan tarik tertinggi. Berdasarkan hal-hal tersebut peneliti ingin meneliti apakah material pin mempergaruhi kualitas sambungan FSW.

\section{Metode Penelitian}

\subsection{Alur Penelitian}

Gambar 1 menggambarkan alur penelitian ini.

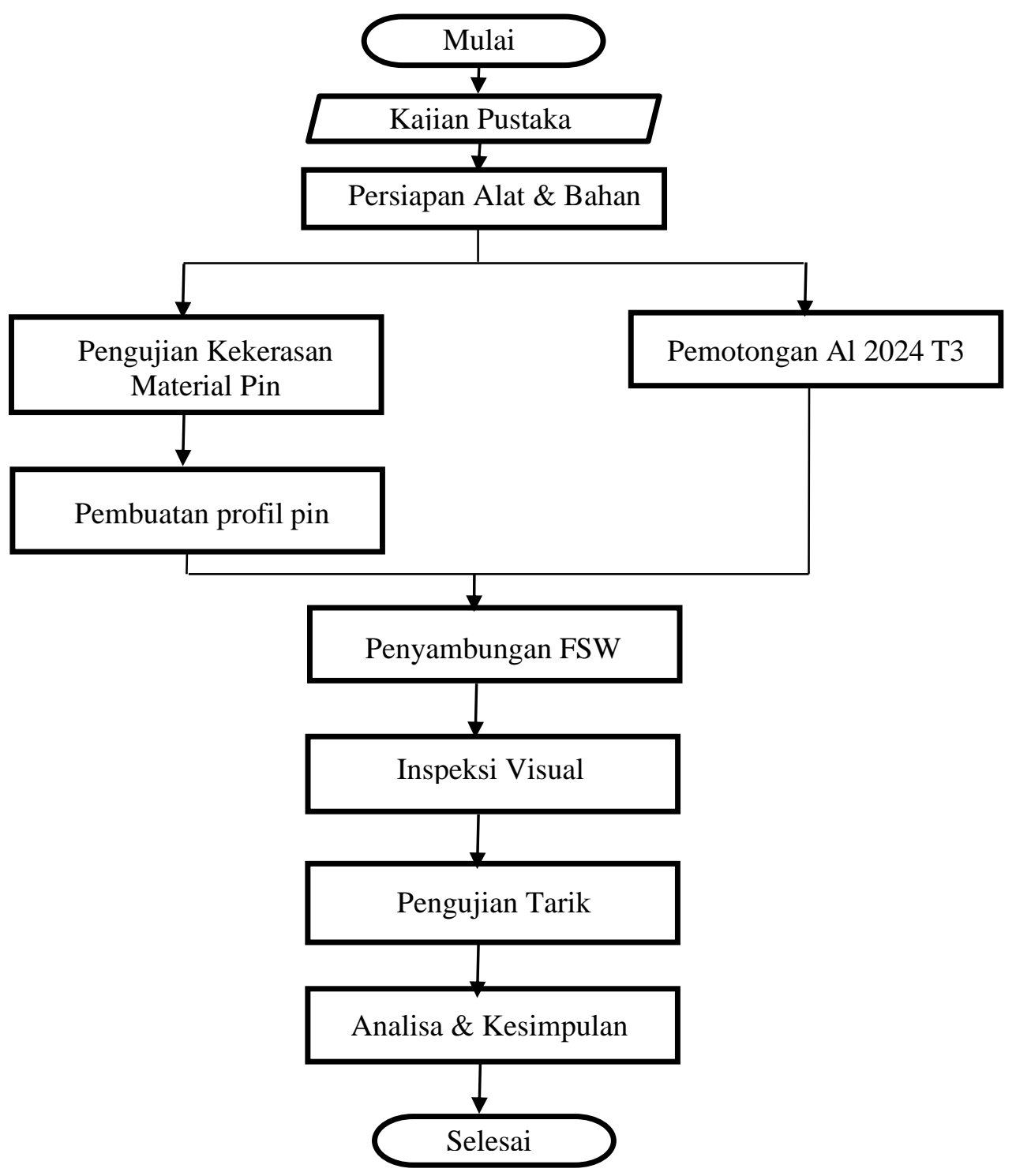

Gambar 1. Alur Penelitian 


\subsection{Identifikasi masalah}

Identifikasi masalah merupakan pernyataan yang lengkap mengenai ruang lingkup pembahasan permasalahan yang akan diteliti, sehingga dapat mengarahkan penulis mengenai penelitian yang dilaksanakan. Setelah melakukan identifikasi masalah, dapat menentukan tujuan dari penelitian yang sedang dilaksanakan.

2.3 Persiapan alat \& bahan

Mengumpulkan alat dan bahan yang dibutuhkan untuk keperluan penelitian seperti Al 2024 T3, material pin, persiapan mesin mill, dll

2.4 Pengujian kekerasan material pin

Pengujian awal untuk mengetahui kekerasan masing-masing material pin menggunakan alat uji kekerasan dengan indentor vickers pembebanan $100 \mathrm{kgf}$

2.5 Pembuatan profil pin

Dengan bantuan mesin bubut dibuat profil silinder dari pin FSW (Gambar 2).

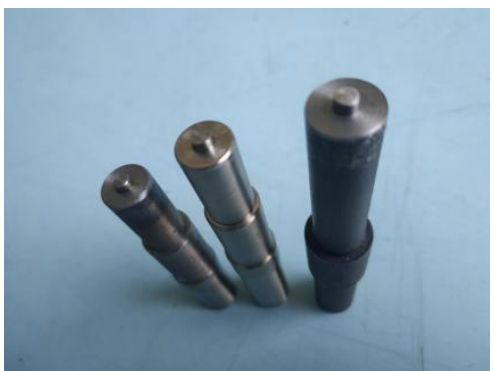

Gambar 2. Pin FSW

\subsection{Pemotongan Al 2024 T3}

Melakukan pemotongan lembaran alumunium sehingga siap disambung secara FSW.

2.7 Penyambungan FSW

Dengan bantuan mesin mill, dilakukan penyambungan dengan pin FSW yang memiliki perbedaan material. Mesin mill diatur dengan parameter permesinan feed rate $60 \mathrm{~mm} / \mathrm{menit}$, putaran spindle 1800 rpm dengan tilt angle mesin $3^{\circ}$. Selama proses juga dilakukan perekaman temperatur dengan infrared thermogun (Gambar 3).

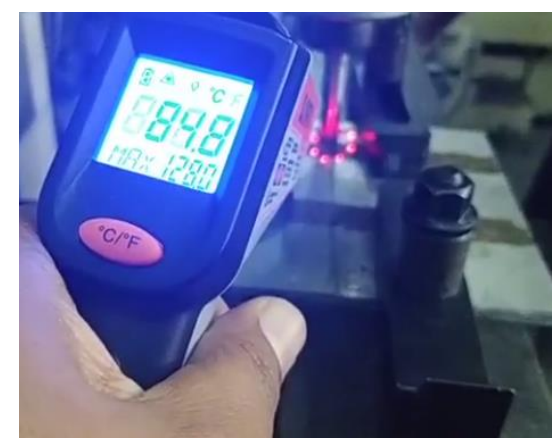

Gambar 3. Penyambungan FSW dengan pencatatan temperatur

\subsection{Inspeksi visual}

Tahapan ini dilakukan assesment secara visual atas sambungan. Langkah ini untuk memastikan secara visual lasan sudah memiliki kualitas yang baik

2.9 Pengujian tarik

Dilakukan pengujian tarik dengan mesin Go-Tech kapasitas 30 ton untuk mendapatkan data dan kurva stress-strain

2.10 Analisa \& Kesimpulan 
Tahapan analisa adalah untuk mempelajari data yang di dapat dan mencoba melakukan pembahasan atas fenomena yang terjadi. Terakhir, ditarik kesimpulan atas penelitian ini.

\section{Hasil \& Pembahasan}

\subsection{Pengujian Kekerasan}

Pengujian kekerasan dilakukan pada ketiga variasi material pin. Hal ini dilakukan untuk mengetahui urutan kekerasan masing-masing material. Pengujian dilakukan menggunakan indentor Vickers dengan pembebanan 100kgf. Nilai tertinggi didapat oleh SS sebesar $1520 \mathrm{HV}$, diikuti ole ST60 Hardened 1055 HV dan material terlunak pada penelitian ini adalah ST60 sebesar $821 \mathrm{HV}$. Tabel 1 dan Gambar 4. menunjukkan hasil penelitian tersebut.

Tabel 1. Hasil Pengujian Kekerasan Variasi Material Tool Pin

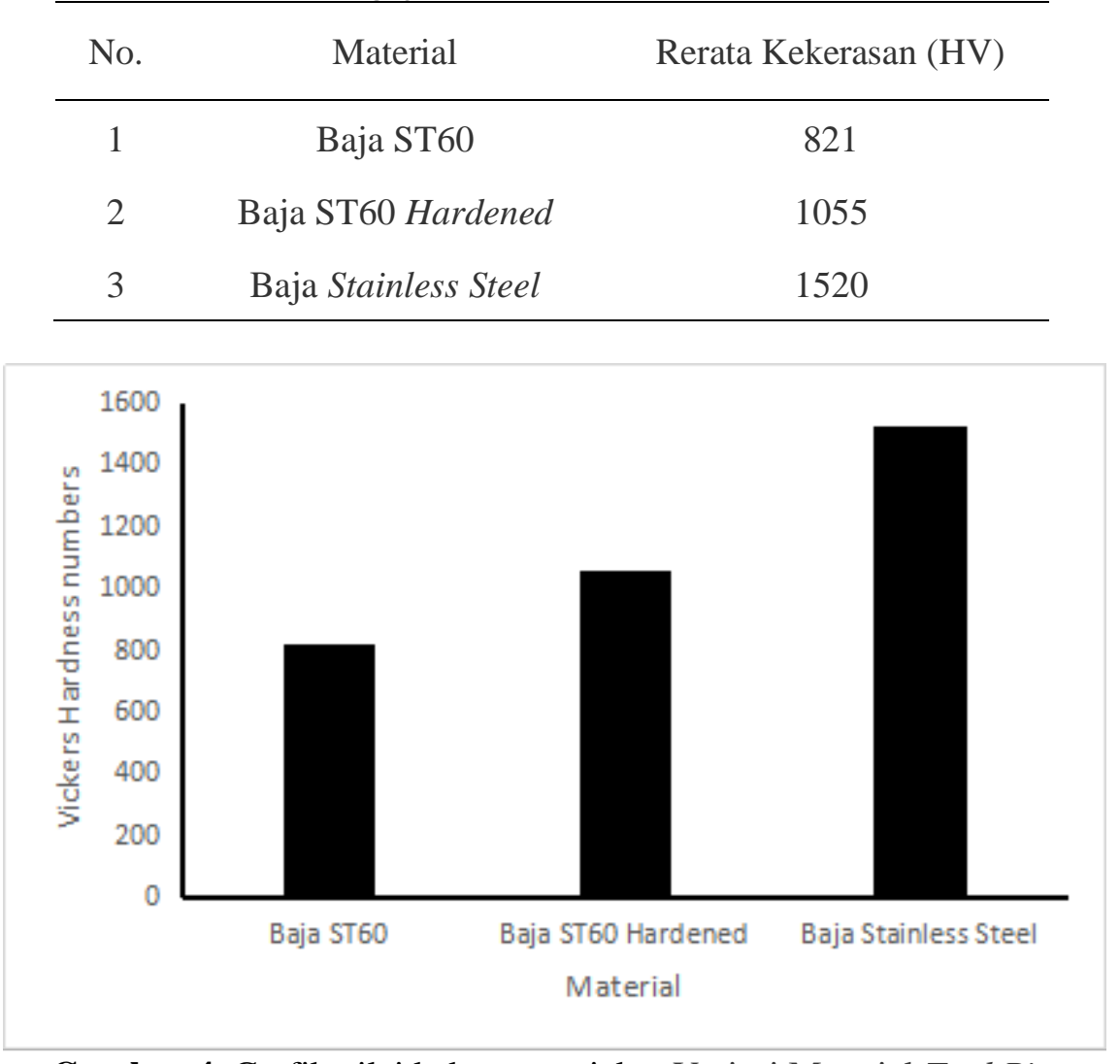

Gambar 4. Grafik nilai kekerasan vicker Variasi Material Tool Pin

\subsection{Inspeksi Visual}

Untuk menjamin kualitas hasil pegelasan FSW, inpeksi visual dilakukan untuk melihat kualitas sambungan dari masing-masing variasi material pin. Gambar 5 menunjukkan hasil citra sambungan FSW. Dari semua sambungan tidak terlihat cacat coran yang nampak, rigi-rigi las yang dihasilkan juga rapat dan terlihat dalam. Hal ini menjamin kekuatan pengelasannya [9].
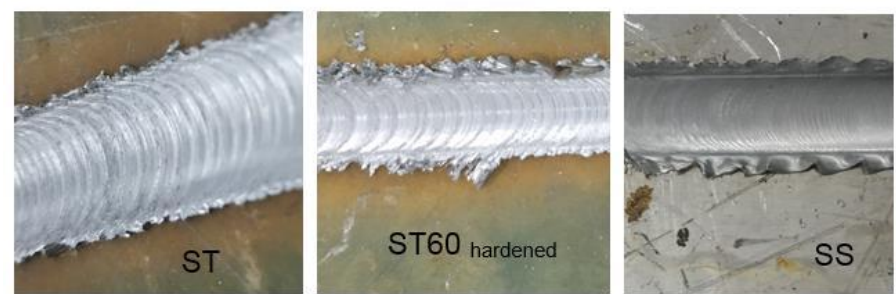

Gambar 5. Kualitas pengelasan FSW variasi material pin 


\subsection{Pencatatan Temperatur Kerja}

Selama pengujian tarik, thermogun infra red diarahkan di area penyambungan. Gambar 3.3 menunjukkan temperatur dengan waktu sampling per 5 detik. Dalam gambar 6 terlihat material pin S60 hardened menghasilkan rerata temperatur tertinggi. Hal ini dimungkinkan karena permukaan luar material yang dikeraskan cederung lebih kasar dibandingkan yang lain. Pin material ST60 hardened dibentuk sebelum proses pengerasan luar. Pengerasan luar merubah kekasaran permukaan dari pin, hal ini berarti meningkatkan kenaikan temperatur saat gesekan dengan material dibanding yang lain [10]. Tabel 2 menunjukkan nominal besaran rerata temperatur penyambungan FSW dengan variasi material pin

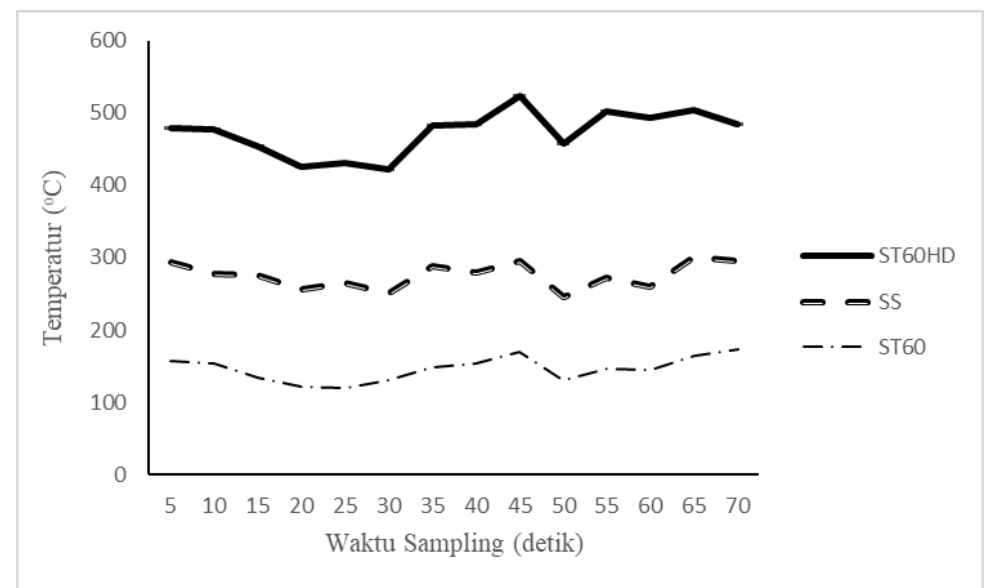

Gambar 6. Sampling temperatur sambungan FSW

Tabel 2. Rerata Temperatur Variasi Material Tool Pin

\begin{tabular}{ccc}
\hline No. & Material & Temperatur $\left({ }^{\circ} \mathrm{C}\right)$ \\
\hline 1 & Baja ST60 & 129 \\
2 & Baja ST60 Hardened & 146 \\
3 & Baja Stainless Steel & 198 \\
\hline
\end{tabular}

\subsection{Pengujian Tarik}

Pengujian tarik menggunakan standar pengujian ASTM E8, dengan mesin go tech kapasitas 30 ton. Gambar 7 memperlihatkan masing-masing variasi material pin, tiap sambungan diambil 3 sample untuk diuji tarik. Berdasar bentuk kurva tegangan-regangan yang terlihat hampir semua material fracture sesaat setelah mencapai ultimate tensile stress (UTS). Bahkan area plastis hampir tidak tampak dari ketiganya, Hal ini berarti sambungan lebih getas dibanding material aslinya. 


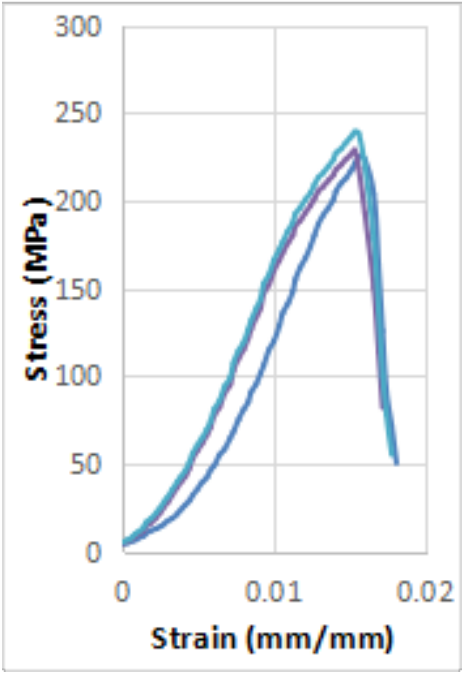

(a)

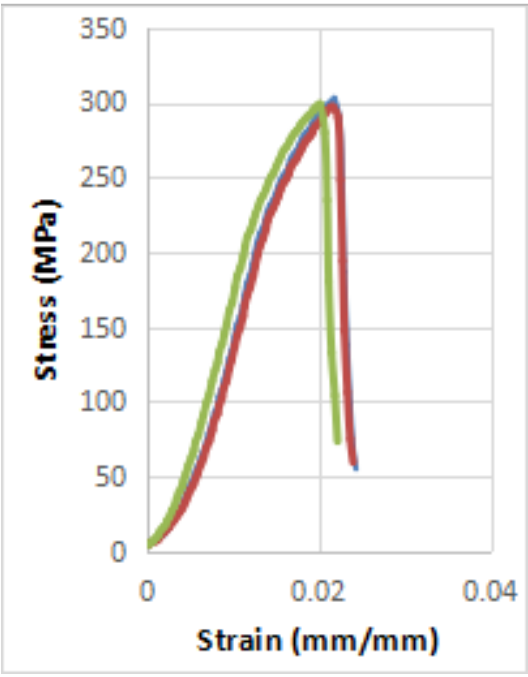

(b)

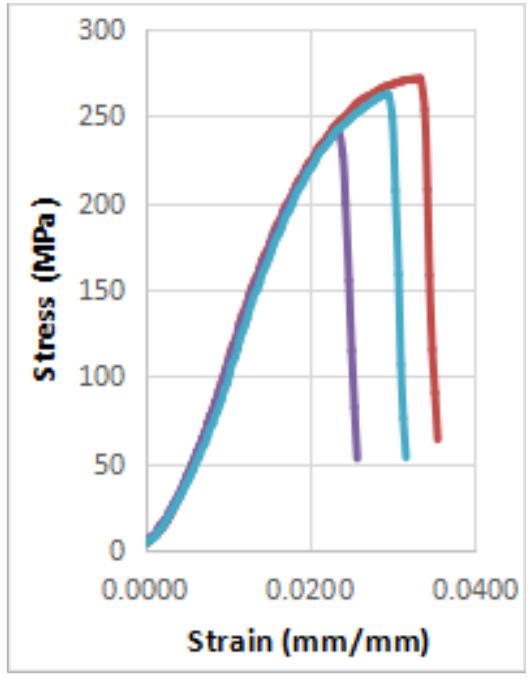

(c)

Gambar 7. Pengujian tarik variasi kekerasan material pin (a) ST60, (b) ST60 Hardened, (c) Stainless steel

Tabel 3 menampilkan hasil pembacaan UTS dan yield strength (YS) atas ketiga sambungan. UTS dan yield strength terbesar didapat pin dengan material ST60 hardened dengan UTS 300 MPa dan YS 250 $\mathrm{MPa}$, berikutnya adalah material stainless steel dengan UTS $259 \mathrm{MPa}$ dan YS $242 \mathrm{MPa}$, dan terakhir adalah ST60 dengan UTS 208 MPa dan YS 231 MPa. Besarnya UTS yang diperoleh materal SY60 hardened adalah karena kekasaran permukaan akibat proses hardened yang dilaluinya. Kekasaran ini meningkatkan pembangkitan panas saat terjadinya gesekan pada proses FSW. Panasnya ini menyebabkan pelunakan material sehingga lebih fluid dibanding yang lain. Hal ini menyebabkan proses pengadukan material lebih mudah dan uniform sehingga menghasilkan pengelasan yang minim cacat. Stainless steel menjadi sambungan dengan kekuatan sambungan di bawah ST60 hardened. Meski memeiliki kekerasan lebih tinggi dibanding ST60 hardened tetapi ternyata tidak terlalu banyak berpengaruh dalam proses penyambugan FSW ini, Kekasaran pin stainless steel lebih halus dibanding material ST60 hardened akibat permesinan. Halusnya permukaan hasil pembubutan ini mengurangi besarnya gesekan antara pin dengan material sehingga temperatur yang dibangkitkan tidak paling tinggi. Sehingga pengadukan akan menjadi tidak sebaik pengadukan proses dengan pin ST60 hardened. UTS terendah diperoleh sambyangan dengan pin ST60, meski memiliki kekasaran yang hampir sama dengan stainless steel, kekerasan material mempengaruhi deformasi awal saat pin ditekan ke material. Pin stainless steel dengan kekerasan yang lebih tinggi menghasilkan defotmasi lebih besar ke material sehingga meningkatkan tekanan yang berakibat meningkatkan temperatur saat penyambungan FSW ini..

Tabel 3. Hasil Pengujian Tarik Variasi Material Tool Pin

\begin{tabular}{cccc}
\hline No. & Material & Yield Strength $(\mathrm{MPa})$ & UTS (MPa) \\
\hline 1 & Baja ST60 & 208 & 231 \\
2 & Baja ST60 Hardened & 250 & 300 \\
3 & Baja Stainless Steel & 242 & 259 \\
\hline
\end{tabular}




\section{Kesimpulan}

Penelitian atas kekuatan Tarik sambungan Al 2024 T3 FSW dengan variasi material tool telah dilaksanakan. Tool divariasikan dengan menggunakan material ST60, ST60 hardened, dan SS berdasarkan kekerasan materialnya. Material terkeras adalah SS dengan nilai sebesar $1520 \mathrm{HV}$, diikuti ST60 hardened sebesar $1055 \mathrm{HV}$, dan paling kecil adalah ST60 sebesar $821 \mathrm{HV}$. UTS diperoleh oleh sambungan dengan pin ST60 hardened sebesar $300 \mathrm{MPa}$ dan YS $250 \mathrm{MPa}$, diikuti SS dengan UTS sebesar $259 \mathrm{MPa}$ dan YS $242 \mathrm{MPa}$, yang terkecil dalam penelitian ini adalah baja ST60 dengan nilai UTS $231 \mathrm{MPa}$ dan YS $208 \mathrm{MPa}$. Temperatur rerata tertinggi didapatkan oleh ST60 hardened, hal ini dikarenakan permukaan shoulder pin dan pin-nya memiliki kekasaran yang lebih tinggi dibanding materi yang lain hasil prses pengerasan.

\section{Daftar Pustaka}

[1] Huda, Z., Taib, N. I., \& Zaharinie, T. 2009. Characterization of 2024-T3: An aerospace aluminum alloy. Materials $\quad$ Chemistry and Physics, 113(2-3), 517. https://doi.org/10.1016/j.matchemphys.2008.09.050

[2] Kundu, J., Ghangas, G., Rattan, N., \& Kumar, M. 2017. Friction Stir Welding : Merits over other Joining Processes. International Journal of Current Engineering and Technology 7(3), 2017, 7, $1175-1177$

[3] Jiang, W. H., \& Kovacevic, R. 2004. Feasibility study of friction stir welding of 6061-T6 aluminium alloy with AISI 1018 steel. Proceedings of the Institution of Mechanical Engineers, Part B: Journal of Engineering Manufacture, 218(10), 1323-1331. https://doi.org/10.1243/0954405042323612

[4] Chien, C., Lin, W., \& Chen, T. 2011. Optimal FSW process parameters for aluminum alloys AA5083. 3839. https://doi.org/10.1080/02533839.2011.553024

[5] PradeepKumar, M., Amarnath, K., \& SunilKumar, M. 2015. A Review on Heat Generation in Metal Cutting. International Journal of Engineering and Management Research, 4(4), 193-197.

[6] Dialami, N., Cervera, M., \& Chiumenti, M. 2019. Effect of the tool tilt angle on the heat generation and the material flow in friction stir welding. Metals, 9(1). https://doi.org/10.3390/met9010028

[7] Luhur P, H. A., Hadi, E. S., \& Amiruddin, W. 2017. Jurnal teknik perkapalan. Teknik Perkapalan, 5(2), 421-430.

[8] Nik, Z. C., Ishak, M., \& Othman, N. H. 2017. The Effect of Tool Pin Shape of Friction Stir Welding (FSW) on Polypropylene. IOP Conference Series: Materials Science and Engineering, 238(1). https://doi.org/10.1088/1757-899X/238/1/012003

[9] Deshmukh, A. R., Venkatachalam, G., Divekar, H., \& Saraf, M. R. 2014. Effect of weld penetration on fatigue life. Procedia Engineering, 97, 783-789. https://doi.org/10.1016/j.proeng.2014.12.277

[10] Everts, M., Ayres, S. R., Mulock Houwer, F. A., Vanderwagen, C. P., Kotze, N. M., \& Meyer, J. P. 2014. The influence of surface roughness on heat transfer in the transitional flow regime. Proceedings of the 15th International Heat Transfer Conference, IHTC 2014, January. https://doi.org/10.1615/ihtc15.cnv.008338 
Istyawan Priyahapsara, Sri Mulyani

MdM-106 